\title{
Championing scientist migration
}

\author{
Science thrives on the free exchange of ideas and collaboration between diverse groups, with researcher mobility \\ greatly accelerating progress. With isolationist rhetoric increasingly dominating the political discourse in many \\ countries, it is important to recognize the value of migration in science.
}

$\mathrm{O}$ ne of the most famous story cycles from One thousand and one nights is that of Sinbad the sailor. Restless, adventurous, inquisitive and resourceful, Sinbad never stayed in his home city of Basra for very long, but set out time and again to travel the seas and make his fortune in foreign lands. Although not faced with mythical beings that threaten their existence (bar, perhaps, the near-mythical, hard-to-satisfy Referee \#3), many scientists emulate Sinbad's spirit through their openness to travel the world in search of the best conditions to study and pursue their research goals.

Migration has been an integral part of human history and has helped science flourish through the physical movement of people, and the dissemination of ideas and expertise. Many scientists nowadays are, or have at some stage been migrants either by studying, teaching or performing research in foreign academic institutions, or by working in the biotechnology, pharmaceutical and biomedical sectors. Thus, the scientific diaspora is a large, diverse and thriving global community. The United Nations Educational, Scientific and Cultural Organisation's 2016 'Science Report: Towards 2030' (https:// go.nature.com/2wFVwYQ) notes that the number of international students enrolled in tertiary education more than doubled between 1995 and 2013, with science and engineering degrees ranking highest in popularity. This international student body is very diverse, with the Arab States and countries of central Asia, sub-Saharan Africa and Western Europe contributing more students than other regions. The same time period marked a surge in the number of international students pursuing $\mathrm{PhDs}$ in science and engineering. Notably, the United States of America was the host country of $49.1 \%$ of these doctoral candidates, with the United Kingdom a far second destination of preference for $9.2 \%$, closely followed by France (7.2\%). Overall, foreign students made up a substantial $\sim 30-40 \%$ of $\mathrm{PhD}$ candidates in these countries. A separate study reported that approximately 1 in 6 healthcare professionals in the US are foreign-born (https://go.nature. com/2CjaTWW).

Regardless of one's sense of adventure, leaving home is not always easy. Economic conditions, the quality and extent of education and research opportunities, as well as immigration policies are crucial in shaping these decisions. Language, geography and cultural affinity are also important in the choice of host country. Beyond gaining access to a better education, developing specialised skillsets and pursuing one's research programme of choice, scientist mobility can be very enriching on a personal level as it exposes individuals to different cultures and can generate vibrant learning, working and living environments.

Proponents of scientific mobility often list the lauded scientists who achieved recognition as migrants as evidence that migration is beneficial for countries. However, one does not have to be a Nobel-prize-winning Albert Einstein or Rita Levi-Montalcini to be a valuable contributor to his/her home and host countries. Enabling the cross-border movement of scientists enhances international collaboration and fosters the cross-fertilization of ideas and technical knowhow to drive innovation and growth. The host country not only benefits from having access to a global talent pool and the opportunity to retain the most promising scientists, but also from the injection of foreign capital from international students. Conversely, by investing in the high-quality training of talented individuals overseas, the home country strengthens its educational, research and innovation capacity once they return.

Traditionally, governments have fostered scientist mobility through policies aimed to attract the best and brightest, but the shifting global economy and political climate have shaken this landscape. Critics of scientific globalisation are concerned about the brain drain that occurs when opportunities and infrastructure in the home country cannot match those in destinations that are superior in science and technology; this downside was felt acutely by some European countries that were hit by the recent financial crisis. In addition, helping foreign nationals (who may ultimately return home) develop highly specialised skillsets, is seen in some quarters as potentially undercutting the host country's global competitiveness. Indeed, recent changes in the US political landscape have led to tighter immigration and visa policies that are also affecting scientists (https:// go.nature.com/2AKs $2 \mathrm{Zv}$ ). Concurrently the enrolment of foreign students in US programmes has decreased since 2015 (https://go.nature.com/2TMfyb1) and it remains to be seen whether this trend will continue.

On the other side of the pond, 2.5 years after the referendum that decided the departure of the UK from the European Union and two months before the deadline for withdrawal, the Brexit debate rages on. UK scientists have long been warning that cutting ties with the EU will be detrimental (https://go.nature.com/2JbpJS9). At the time of writing, UK Parliament has rejected the government-backed Brexit deal and is preparing to discuss the next steps, so all possibilities remain open. A no-deal Brexit would be catastrophic for the UK's ability to conduct high level research and attract top talent from the EU. However, the government's draft agreement did not clarify future immigration policy (https://go.nature.com/2HcuOMZ) and it is unclear what revisions would make it acceptable to Parliament. The possibility that the UK will reverse course and stay in the EU still exists, but appears remote.

In the face of isolationism it is important to remember that research progress requires co-operation, inclusivity and exchange of knowledge. Helping gifted scientists work together, by creating policies that encourage migration and foster cross-cultural interaction, is crucial.

Our theme this month is migration, and fittingly so, as we are also saying farewell to our Chief Editor, Alexia-Ileana Zaromytidou. After almost 8.5 years at the journal and more than 3 years at the helm, Alexia is embarking on an exciting new venture as the launch Chief Editor of Nature Cancer, the latest addition to the Nature journal family. We will miss Alexia's editorial wisdom, mentorship, passion for science and commitment to the journal. Under her leadership, Nature Cell Biology has further developed the editorial process around data transparency, reproducibility and research ethics. She has also launched numerous exciting projects, such as the 'Focus on Women in Science' (https://go.nature.com/2DacLmF) and the celebration of our 20-year anniversary (https://go.nature.com/2QM9HQT), which have been well-received in the community. We wish Alexia the best in her new role, and look forward to the novel directions Nature Cell Biology will take in the future.

Published online: 1 February 2019 https://doi.org/10.1038/s41556-019-0283-8 